\title{
Effect of an intervention on performance regarding change of tracheostomy tube among the caregivers of the patient
}

Manisha Nagi, Surinder Kapoor ${ }^{1}$, Sukhpal Kaur ${ }^{1}$, S. K. Gupta²

Neurosurgery Unit, ${ }^{1}$ National Institute of Nursing Education, ${ }^{2}$ Department of Neurosurgery, PGIMER, Chandigarh, India

\section{A B S T R A C T}

Background: Majority of the stable patients after neurosurgery requiring long-term care are discharged with tracheostomy tube (TT) in situ. The caregivers need to learn the technique of change of TT at home. Aims: The current study talks about the effect of an intervention on the performance regarding change of TT among the caregivers of the patients who are going to be discharged with a TT in situ. Materials and Methods: The study was carried out in the Department of Neurosurgery of a tertiary care hospital. Sixty-four subjects were purposely selected. The tools used were identification data sheet and an observation checklist on the change of TT. First, the caregivers were observed during change of TT. Then, each subject was demonstrated the right technique of change of tube. Statistical Analysis and Results: Majority of the subjects (89.1\%) were male $70.3 \%$ were married. Age of the subject was in the range of $18-60$ years, with a mean age of $30.7 \pm 8.9$ years. The maximum attainable performance score of the change of TT was 16 . Before demonstration, only one subject had some knowledge about the change of TT. After $72 \mathrm{~h}$ of demonstration, the score was $12.34 \pm 1.6$ (77.2\%). Conclusion: It is recommended that the caregivers should be properly trained regarding changing the TT in order to prevent any complication while performing the procedure. The results of this study provide further strategies for other caregiver guidance programmes.

Key words: Caregiver, changing tracheostomy tube, performance

\section{INTRODUCTION}

The placement of a tracheostomy tube (TT) secures the airway for patients who require prolonged invasive mechanical ventilation. ${ }^{[1,2]}$ These patients may have upper airway obstruction, may have undergone a laryngectomy or may be having difficulty in managing secretions. Many patients requiring long-term care get discharge with tracheostomy in situ. Patients with tracheostomy are at risk for serious and potentially life-threatening complications. First, TT change is performed once the tracheotomy tract has matured. It is usually performed after 7-14 days of placement. The first TT change carries more risk and should be performed by a skilled person. ${ }^{[3]}$

The indications for a first TT change include downsizing the tube to improve patient comfort, to reduce pressure on the tracheal mucosa by reducing the tube external

\begin{tabular}{|l|l|}
\hline \multicolumn{2}{|c|}{ Access this article online } \\
\hline Quick Response Code: & Website: \\
\hline & www.jins.in \\
\cline { 2 - 3 } & \\
\hline
\end{tabular}

diameter and to facilitate speech. ${ }^{[4,5]}$ The other indications for changing the tube include malpositioned tube due to incorrect length or size, patient-ventilator asynchrony or the problems related to TT-like cuff leak, tube or flange fracture, etc.

Changing an established TT is usually safe and easily done. The risk associated with changing the TT usually diminishes over time as the tracheo-cutaneous tract matures. A malpositioned tube can be a source of patient distress. ${ }^{[6]}$ Therefore, the patient and the caregivers need to be instructed for home care. This includes changing and cleaning the tube and suctioning of the trachea. ${ }^{[7]}$ It is essential that all caregivers should have comprehensive and thorough training regarding the proper care of the patient with tracheostomy. Training should begin as early as possible. ${ }^{[8]}$ It should be individualized to the patient and should include basic airway anatomy, signs and symptoms of respiratory and upper airway distress, signs and symptoms of aspiration, suctioning technique, tube change procedure, articles required and the financial issues. ${ }^{[9]}$ Previous interventions and studies have shown improved caregiver outcomes when nurses are involved to develop skills among the caregivers regarding patient care. ${ }^{[10]}$

In a tertiary care hospital that bears with an unexplained

Address for correspondence: Ms. Manisha Nagi,

Clinical Instructor, PGIMER, Chandigarh, India. E-mail: manisha_negi86@yahoo.com 
burden of hospitalized patients, many stable patients are discharged with the TT in situ. An increasing number of tracheostomy-dependent patients are sent home for long-term home management. Hence, the current study was undertaken to assess the effect of an intervention on the performance level of the subjects (caregivers) regarding change of TT.

\section{MATERIALS AND METHODS}

The study was carried out in the neurosurgery units of Nehru Hospital, PGIMER, Chandigarh. Using the purposive sampling technique, 64 caregivers between the age group of $18-60$ years and those who were involved in the direct care of the patients were included in the study.

An identification data sheet was used to collect the basic information regarding the patients and the caregivers. A pre-validated observation checklist on change of TT containing 16 steps was developed to evaluate the performance of the subjects. For every correct step, 1 score and for every wrong or missed step 0 score was given to the subjects. An information booklet on change of TT was also developed. It was prepared in English and Hindi languages. The booklet contained information regarding anatomy and physiology of the respiratory system, tracheostomy and its purposes and change of TT. The content validity of the tools was established by circulating the tools among the experts in the related fields. Reliability of the tool was checked by using interrater Cohn's kappa reliability (0.90). Subjects were asked regarding previous experience of change of situation, any training on the change of TT and whether they could provide independent care to their patients at home.

First, the caregivers were observed during change of TT. Then, each subject was demonstrated the right technique of changing the TT. It was followed by having one return demonstration of the changing of TT from each subject on the third day of demonstration. During return demonstration, each subject was corrected if he/she followed any wrong step.

This study was approved by the Institute Ethics Committee. A written permission was taken from the Head, Department of Neurosurgery, PGIMER, Chandigarh. Written consent was obtained from each selected subject.

SPSS (version16.0) was used to analyze the data.

\section{RESULTS}

Table 1 highlights the socio-demographic profile

\begin{tabular}{lc}
\hline $\begin{array}{l}\text { Table } 1 \text { : Socio-demographic profile of subjects } \\
\text { (caregivers) } N=64\end{array}$ \\
\hline Personal characteristics & $n(\%)$ \\
\hline Age (years) & \\
$\leq 20$ & $3(4.7)$ \\
$21-40$ & $49(76.6)$ \\
$\quad 41-60$ & $12(18.7)$ \\
Mean \pm SD: 30.7 (years) \pm 8.9 & \\
Range: $18-60$ (years) & \\
Gender & \\
$\quad$ Male & $57(89.1)$ \\
Female & $7(10.9)$ \\
Locality & \\
Rural & $44(68.8)$ \\
Urban & $20(31.2)$ \\
Marital status & \\
$\quad$ Married & $45(70.3)$ \\
$\quad$ Unmarried & $19(29.7)$ \\
Educational status & \\
Just literate & $7(10.9)$ \\
Up to matric & $23(35.9)$ \\
Senior secondary & $23(35.9)$ \\
Graduation and above & $11(17.3)$ \\
Occupation & \\
$\quad$ Not working & $15(23.4)$ \\
Private & $37(57.8)$ \\
Government & $4(6.3)$ \\
Others\# & $8(12.5)$ \\
\hline
\end{tabular}

"House wife, driver, etc

of the subjects. The subjects were in the range of $18-60$ years, with a mean age of $30.7 \pm 8.9$ years. Around three-fourth $(76.6 \%)$ of the subjects were in the age group of $21-40$ years. Majority $(89.1 \%)$ of the subjects were male $70.3 \%$ were married $35.9 \%$ each were educated up to matric and senior secondary.

Effect of intervention on the performance score of the subjects

Figure 1 depicts the comparison of mean performance scores of the subjects before and after demonstration of the change of TT. The maximum attainable score was 16. Before the demonstration, the mean performance score was $0.16 \pm 1.3$. In the return demonstration, which was taken at $72 \mathrm{~h}$, the mean performance score increased to $12.34 \pm 1.6(t=-48.17,63, P<0.0001)$.

No. of subjects performing correct steps of the change of TT in baseline observation and in the return demonstration Table 2 highlights the number of subjects who performed the correct steps of the change of TT in baseline and in the return demonstration, i.e. after $72 \mathrm{~h}$. The whole procedure was divided into 16 steps. It included the steps before the change of the TT, during the change of the TT and after the change of the TT. There was 


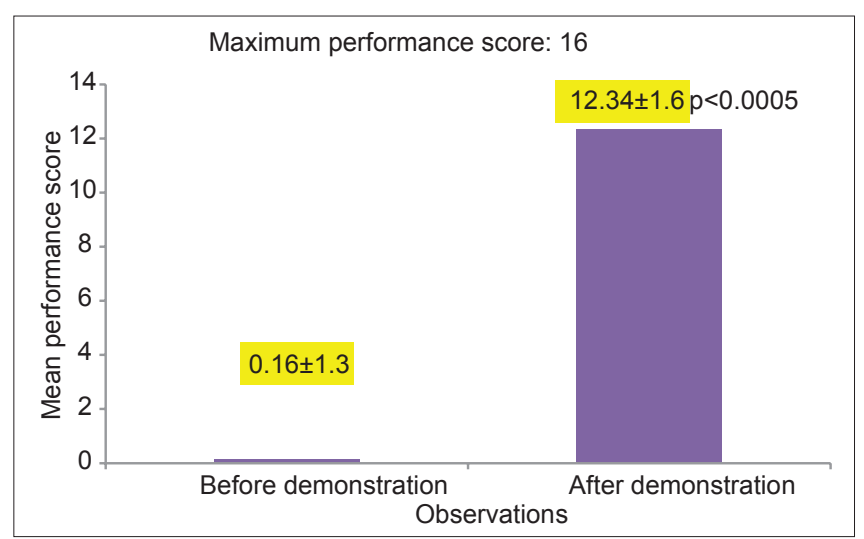

Figure 1: Mean performance score of the subjects in the change of tracheostomy tube before and after demonstration

Table 2: No. of subjects performing correct steps of the procedure before and after demonstration $N=64$

\begin{tabular}{lll} 
Steps & \multicolumn{2}{c}{$n$ (\%) } \\
\cline { 2 - 3 } & $\begin{array}{c}\text { Before demo } \\
\text { (baseline) }\end{array}$ & $\begin{array}{c}\text { After } \\
\text { demo }\end{array}$ \\
\hline Before the change of TT & & $50(78.1)$ \\
Assessed the need for the patient & 1 & $54(84.4)$ \\
Brought all the articles at the bed side & 1 & $46(71.9)$ \\
Provided extended position & 0 & $61(95.3)$ \\
Washed hands & 1 & $54(84.4)$ \\
Deflated the balloon of tube in situ & 1 & $53(82.8)$ \\
Loosened the previous tube ties & 1 & $52(81.3)$ \\
Removed the tube in situ & 1 & $61(95.3)$ \\
Donned sterile/clean gloves & 1 & $40(62.5)$ \\
During the change of TT & & $51(79.7)$ \\
Cleaned the stoma with saline gauze & 1 & $27(42.2)$ \\
Applied lubricating gel on the tube & 1 & $22(34.4)$ \\
Inserted tube first laterally & 0 & $39(60.9)$ \\
Rotated the tube perpendicular to the & 0 & $42(65.6)$ \\
body and removed the stylet & & $56(87.5)$ \\
Checked the airway entry & 0 & 61 (95.3) \\
Inflated the tube & 0 & \\
Tied the tube properly & 0 & \\
After the change of TT & 1 & \\
Stored the tube appropriately & & \\
\hline TT - Tracheostomy tube & &
\end{tabular}

only one subject who had some baseline knowledge regarding change of TT. After demonstration, there was a significant improvement in the performance score of the subjects while changing TT. Almost all (95.3\%) subjects performed hand washing before the procedure, donned clean gloves and stored the tube appropriately after the procedure, which was followed by tying the tube properly. Majority (87.5\%) of the subjects performed that step correctly. On the other hand, $42.2 \%$ inserted the tube properly. $34.4 \%$ rotated the tube properly and removed the stylet. Maximum (around 60\%) subjects had difficulty in inserting the tube properly that was followed by checking airway entry. $60.9 \%$ checked airway after inserting the tube.

\section{DISCUSSION}

In the tertiary care hospital of our country, because of more critical care patient influx and constraints regarding beds, manpower and staff, there arises a need for shifting stable patients from the tertiary care centers to primary health centers. In view of this, large patient load and huge number of patients in vegetative/dependent states are being discharged from these hospitals to primary care centers, or the caregivers are asked for the home management of the patients. The number of patients who require tracheostomy care at home or at the local medical centers has increased. The caregivers are constantly challenged to solve problems and make decisions as per the needs of the patients at home. The co-morbidities in neurosurgery patients can easily be prevented and managed and the quality of life of these patients can be improved if proper nursing care is provided to them at home after discharge.

Change of TT is a critical procedure that needs appropriate skills. Thus, the caregivers need to be provided with training for tracheostomy care. ${ }^{[11]}$ The nursing staffs play a vital role in providing education, training and support to the patients being discharged with tracheostomy in situ and to their caregivers. ${ }^{[12,13]}$ When a patient is identified as requiring a long-term or permanent tracheostomy, the complexity of the care needs and safety issues must be kept in mind. It is essential in preventing critical incidents or readmission to hospital. ${ }^{[14]}$

In the current study, it was surprising to see that among the patients who were going to be discharged from the hospital, only one subject had previous experience of handling/changing of TT. Therefore, one can imagine the extent of problem the patients and the caregivers are going to face after getting discharge from the hospital. Ideally, the training of the caregivers in the hospital should be started as early as possible so that they are skilled enough to take care of their patients at home. Hill ${ }^{[15]}$ and Lewarski ${ }^{[9]}$ noted the importance of an early training phase in the discharge plan. Bakewell-Sachs and Porth noted the importance of the family's confidence and competence in the care of their patients prior to discharge and the need for early and progressive training. ${ }^{[16]}$

Most of the caregivers in the present study were more than 18 years of age, and were male. Recent surveys support that there are 44 million caregivers over the age of 18 years. ${ }^{[17]}$ Most caregivers were male who handle time-consuming and difficult tasks like personal care. ${ }^{[18,19]}$ 
A growing trend demonstrated a 50\% increase in male caregivers between 1984 and 1994. ${ }^{\text {[20] }}$

In the present study, all the subjects were given a booklet that they could consult at their homes. In many studies, multiple teaching tools, activities and training sessions, based on adult learning theory, were utilized to develop appropriate clinical skills to manage patients with tracheostomies at home. ${ }^{[10,20,21]}$ Good educational programs incorporate activities for all learning styles and utilize a variety of teaching tools, such as visual aids, illustrations and active participation, to reinforce critical concepts. ${ }^{[22-25]}$ Providing written information of any procedure is recommended by other studies. It provides patients and relatives with a resource that they can refer to at any time and that enhances their skills. ${ }^{[26]}$

The intervention in the current study was quite effective in enhancing the skill of the caregivers. It was seen that only one subject could perform just few steps of change of TT before the demonstration. However, most of the subjects could perform majority of the steps during the return demonstration, which was taken at $72 \mathrm{~h}$ of the demonstration. The step of rotation of tube perpendicular to the body and removal of stylet were performed correctly by the least number of subjects. Here, it needs to be emphasized that it is an important and critical step of change of TT. Any mishandling or mistake during this step can be lethal for the patient. All the subjects were corrected for their mistakes.

The findings have been supported by the results of another study in which 20 caregivers of 10 patients had undergone the tracheostomy care training program for the first time. Data were collected from all the caregivers; there were statistically significant improvements between the caregivers' pre-training and post-training test scores (Wilcoxon signed rank $\mathrm{Z}=3.84, \mathrm{P}<0.001)$. The mean $\pm \mathrm{SD}$ pre-training test score was $35.3 \pm 13.2 \%$ as compared with the post-training mean test score of $91.1 \pm 4.9 \% .{ }^{[11]}$ The findings are also supported by the results of another study that showed that there was a statistically significant improvement in caregiver test scores after the training of tracheostomy care, including suction and tube change $(P<0.001)$. The training program achieved its goal of caregiver preparation. ${ }^{[27]}$

There were few limitations of the study, which included the fact that a relatively small number of caregivers were studied at a single institution. It limits the applicability of the findings related to our specific training program to other centers. Furthermore, the investigator evaluated only the short-term impact of the education program.
It did not evaluate the long-term impact of training on caregivers' performance. Further studies may be carried out to assess the complications and the problems of the caregivers while changing the tube.

\section{CONCLUSION}

Such caregiver training programs should be started especially for the patients requiring long-term care. Ongoing evaluation and refinement of training programs that prepare families for the discharge of their patients with tracheostomy to home should be performed to identify new opportunities for improvement in this process. The study findings provide initial insights into the process of successful training of families for participation in the care of their technology-dependent patients at home.

\section{REFERENCES}

1. White AC, O'Connor HH, Kirby K, White AC, O'Connor HH, Kirby K. Prolonged mechanical ventilation: Review of care settings and an update on professional reimbursement. Chest 2008;133:539-45.

2. Esteban A, Anzueto A, Frutos F, Alia I, Brochard L, Stewart TE, et al. Characteristics and outcomes in adult patients receiving mechanical ventilation: A 28-day international study. JAMA 2002;287:345-55.

3. Schmidt U, Hess D, Kwo J, Lagambina S, Gettings E, Khandwala F, et al. Tracheostomy tube malposition in patients admitted to a respiratory acute care unit following prolonged ventilation. Chest 2008;134:288-94.

4. White AC, Kher S, Connor HH. When to change a tracheostomy tube. Respir Care 2010;55:1069-75.

5. De Leyn P, Bedert L, Delcroix M, Depuydt P, Lauwers G, Sokolov Y, et al. Tracheotomy: Clinical review and guidelines. Eur J Cardiothorac Surg 2007;32:412-21.

6. Deutsch ES, Deutsch ES. Early tracheostomy tube change in children. Arch Otolaryngol Head Neck Surg 1998;124:1237-38.

7. Tracheostomy and ventilator home care. Available from: http://www. focusonals.com/tracheotomy.htm. Retrieved on 30/10/11. [Last accessed on same date].

8. American thoracic society. Available from: http://www.archive.thoracic. org/sections/education/care-of-the-child-with-a-chronic-tracheostomy/ components-of-tracheostomy-care/caregiver-education.html. Retrieved on $20 / 10 / 11$.

9. Lewarski JS. Long term care of the patient with tracheostomy.Respir Care 2005;50:534-7.

10. Lewis T, Oliver G. Tracheostomy: Facilitating successful discharge from hospital to home and improving tracheostomy care for ward patients. Available from: http://margate.tracy.lewis@ekht. Nhs.uk/retrieved on 17 Feb. 2011.

11. Susan CR, Barbara G, Nirvana HP, Ann B. SupportingFamily Caregivers in Providing Care. Bookshelf. Available from: http//www.ncbi.nlm.nih. gov/books. Retrieved on 23/10/11.

12. Tearl DK, Hertzog JH. Home discharge of technology-dependent children: Evaluation of a Respiratory-therapist driven family education program. Respir Care 2007;52:171-6.

13. Edgtton-Winn M and Wright K. Tracheostomy: A guide to nursing care. Aust Nurs J 2005;13:17-20.

14. Bowers B, Scase C. Tracheostomy: Facilitating successful discharge from hospital to home. Br J Nurs 2007;16:476-9.

15. Hill DS. Coordinating a multidisciplinary discharge for the technology- dependent child based on parental needs. Issues Compr Pediatr Nurs 1993;16:229-37. 
16. Bakewell-Sachs S, Porth S. Discharge planning and home care of the technology-dependent infant. J Obstet Gynecol Neonatal Nurs 1995;24:77-83.

17. National Alliance for Caregiving. AARP. Caregiving in the U.S. Bethesda, MD.: National Alliance for Caregiving, AARP; 2004. Apr. Available from: www.caregiving.org/date/04final report.pdf.

18. US Department of Health and Human Services. The future supply of long-term care workers in relation to the aging baby boom generation. Report to Congress. Washington. DHHS and DOL; 2003. Available from: http://aspe.hhs.gov/daltcp//reports/itcwork.pdf. [Last accessed on same date].

19. Spillman BC, Pezzin LE. Potential and active family caregivers. Changing networks and the "sandwich generation. Milbank 2000;78:347-74.

20. Levine $\mathrm{H}$, Miller C. Tracheostomy care manual. $2^{\text {nd }}$ ed. New York: Thieme; 1988.

21. Smith Miller CA. Reason for customize a tracheostomy patient education booklet. ORL Head Neck Nurs 205;23:14-21.

22. Fink D. Evaluating your own teaching. Improving college teaching. Improving college teaching. Bolton, Massachusetts: Anker; 1995. 113-30.

23. Lieb S. Principles of adult learning. Arizona Department of Health Services,
South Mountain Community College. Vision; 1991. Available from: wcwpds.wisc.edu/mandatedreporter/adult_learning.pdf. Retrieved on 17 Feb. 2012.

24. Galbraith MW. Facilitating adult learning: A transactional process. Malabar, Florida: Krieger; 1991. p. 1-32.

25. Galbraith MW. Adult learning methods: A guide to effective instruction. Malabar, Florida: Kreiger; 1991. p. 23-38.

26. Fitts PM, Posner MI. Human performance. Oxford, England: Brooks and Cole (1967). Available from: http://www.brianmac.co.uk/tech. htm Skill Developmen/retrieved on 22 Feb. 2012.

27. Shyu YI, Kuo LM, Chen MC, Chen ST. A clinical trial of an individualised intervention programme for family caregivers of older stroke victims in Taiwan. J Clin Nurs 2010;19:1.

How to cite this article: Nagi M, Kapoor S, Kaur S, Gupta SK. Effect of an intervention on performance regarding change of tracheostomy tube among the caregivers of the patient. Indian $\mathrm{J}$ Neurosurg 2014;3:31-5.

Source of Support: Nil, Conflict of Interest: None declared.

\section{Author Help: Reference checking facility}

The manuscript system (www.journalonweb.com) allows the authors to check and verify the accuracy and style of references. The tool checks the references with PubMed as per a predefined style. Authors are encouraged to use this facility, before submitting articles to the journal.

- The style as well as bibliographic elements should be $100 \%$ accurate, to help get the references verified from the system. Even a single spelling error or addition of issue number/month of publication will lead to an error when verifying the reference.

- $\quad$ Example of a correct style

Sheahan P, O'leary G, Lee G, Fitzgibbon J. Cystic cervical metastases: Incidence and diagnosis using fine needle aspiration biopsy. Otolaryngol Head Neck Surg 2002;127:294-8.

- Only the references from journals indexed in PubMed will be checked.

- $\quad$ Enter each reference in new line, without a serial number.

- $\quad$ Add up to a maximum of 15 references at a time.

- If the reference is correct for its bibliographic elements and punctuations, it will be shown as CORRECT and a link to the correct article in PubMed will be given.

- If any of the bibliographic elements are missing, incorrect or extra (such as issue number), it will be shown as INCORRECT and link to possible articles in PubMed will be given. 